
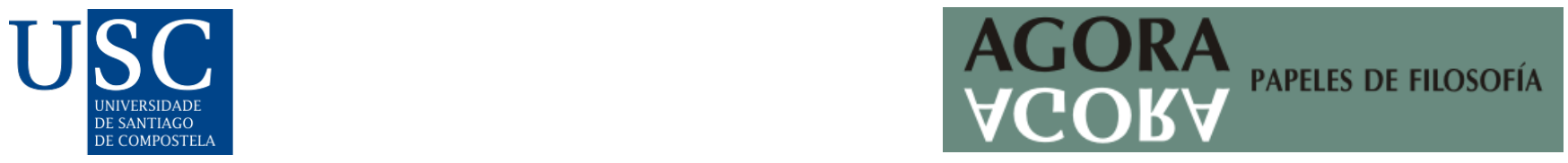

Agora. Papeles de Filosofía, 41(1), 2022. ISSN-e: 2174-3347

https://doi.org/10.15304/agora.41.1.8031

\title{
BRAZ TEIXEIRA, António: A saudade na poesia lusófona africana e outros estudos sobre a saudade, MIL (Movimento Internacional Lusófono) e DG Edições, Linda-a-Velha (Portugal), 2021, 170p.
}

\author{
Luís G. Soto, Miguel A. M. Quintanar
}

Recibido: 20/10/2021; Aceptado: 22/10/2021

Nesse livro, António Braz Teixeira, reputado filósofo e investigador, referência incontornável nos estudos acerca da saudade, realiza uma inquerição, de teor filosófico, sobre a expressão poética da saudade nas literaturas lusófonas africanas e, além disso, revisita algumas formulações notáveis da filosofia da saudade, em Portugal e na Galiza, assim como algumas aproximações, tentativas ou hipotéticas, desde a filosofia espanhola contemporânea. Consequentemente, os estudos estão agrupados em duas partes. A primeira, "Expressão e sentido da saudade na poesia lusófona africana", compõe-se de quatro textos independentes. A segunda parte, os "Outros estudos sobre a saudade", inclui cinco trabalhos.

A "Introdução" (pp.11-15) é um recordatório e uma declaração de intenções. Lembra o autor que, a respeito da saudade em Portugal, Galiza e Brasil, a expressão poética precedeu à sua consideração reflexiva e à constituição de uma filosofia da saudade. Nesta direção, o autor declara que a intenção deste livro não é bosquejar uma interpretação saudosa ou saudosista das literaturas lusófonas angolana, moçambicana, cabo-verdiana e santomense senão, antes, "compreender o sentido que, em cada uma delas, assume a experiência ou a vivência saudosa, as formas e objectos da saudade, os elos subtis e genesíacos que ligam o sentimento saudoso ao amor e à ausência, os nexos entre a lembrança e a esperança ou o desejo, o modo como logra transfigurar ou trans-substancializar as coisas e os seres, através da memória inventiva e criadora que lhe é própria, a sua relação com o sonho ou o tempo sonhado, transcendido ou anulado, numa palavra, perscrutar o significado que, filosoficamente, se pode retirar das diversas formas como a saudade fala por intermédio dos poetas, desvelar ou revelar a filosofia da saudade implícita na poesia saudosista angolana, moçambicana, caboverdeana e santomense" (p. 15). 0 autor defende a pertinência de uma investigação de inspiração e substância filosóficas, não literárias nem histórico-literárias, que se desenvolve no plano da reflexão e a criação conceptual.

O segundo texto, "Expressão e sentido da saudade na poesia angolana" (pp. 16-35), apresenta e analisa a saudade na poesia de vários poetas. José da Silva Maia Ferreira (1827-1881) faz da saudade o resultado da distância, do que provoca o ser amado, inclusive aparecem na sua poesia "tímidos sinais do sentido religativo da saudade" (p. 17). Joaquim Dias Cordeiro da Matta (1857-1894) tende a encerrar-se num entendimento niilista da saudade, de amargo sabor ultrarromântico, enquanto Pedro Félix Machado (c. 1860-1907) nem sequer a toma como motivo ou assunto poético. Tomás 
Vieira da Cruz (1900-1960) aprofunda na consciência da finitude humana que traz consigo a saudade, comprazendo-se num fatalismo triste. Em Geraldo Bessa Victor (1917-1985) a saudade encontra, pela primeira vez, a mais rica e variada expressão, revelando a sua radical dimensão humana, abrindo vias inexploradas para a sua adequada e atenta consideração reflexiva: o tempo (futuro, sonhado, transcendido) e, também, a saudade como imagem e ideia. Agostinho Neto (1922-1979) dá um passo no entendimento da saudade como saudade de nada, daquilo que não foi ou não chegou a ser. António Jacinto (1924-1991) explora a saudade de tal maneira que "surge, pela primeira vez, na poesia de Angola, a dimensão esperançosa ou futurante do sentimento saudoso e uma clara menção ao que há ou pode ter de reminiscência na lembrança de que nasce, pelo que esta poderá ser gerada ou movida por algo que não se conhece ou se não sabe" (p. 21). 0 caso de Mário António (1934-1988) é, para o autor, de idêntica importância a Agostinho Neto. Ares de Almeida Santos (1922-1992) explora a saudade do tempo vivido e a sua ampliação a uma espécie de saudade das saudades sentidas em alguns momentos do passado. Alda Lara (1930-1962) frequenta a saudade da infância e a terra distante, empapada de uma afirmação da esperança, um acento religioso e um sentido da comunhão amorosa. 0 autor também assinala e explica a muito escassa presença da expressão do sentimento saudoso na obra de três poetas: Arlindo Barbeiros (1940-2021), Ruy Duarte de Carvalho (1941-2010) e David Mestre (1948-1998). A seguir, Braz Teixeira repassa os elementos saudosos na obra poética de Maria Alexandre Dáskalos (1957-2021), Joâo Melo (1955), E. Bonavena (1955), Lopito Feijóo (1963), Ondjaki (1977), entre outros. 0 estudo conclui com o desenvolvimento explícito de uma tese: os poetas analisados consideram a saudade exclusivamente desde a dimensão antropológica, estão ausentes as dimensões cósmica e divina da saudade.

0 terceiro texto, "Expressão e sentido da saudade na poesia moçambicana” (pp. 36-61), repassa e expõe os traços da saudade em vozes de Moçambique como Rui de Noronha (1909-1943), Reinaldo Ferreira (1922-1959), Noémia de Sousa (1926-2002), entre outros. No caso de Glória de Sant'Anna (1925-2009) o autor sublinha o seu tratamento pessoal da saudade da natureza ou dos seres naturais. Na lírica de Orlando Mendes (1916-1990) a saudade marca, com frequência, presença, em especial aquela que tem a sua raiz na solidão, a ausência e a distância. Orlando de Albuquerque (1925-1995) concentra sua poesia saudosa na evocação da infância da cidade de Lourenço Marques onde nasceu e de onde, se está fora, se sente exilado. Na poesia de Rui Knopfli (1932-1997) ocupam um lugar significativo a saudade da infância, os familiares mortos e, após o seu exílio forçado em 1975, a saudade da sua terra, Moçambique, e sua cidade, Lourenço Marques. Vergílio Lemos (1929-2013) marca a saudade com os caracteres de uma potência que invade o amor que vence ou transcende a morte, uma esperança que pode ocupar e encher tudo. José Craveirinha (1922-2003) faz um percurso pela saudade provocada pela morte da sua mulher, de tal modo que a palavra poética é capaz de a trazer a uma fecunda presença. 0 autor termina com uma apresentação dos trabalhos poéticos de Eduardo White (1963-2013) centrados na saudade do outro (mulher amada, infância, mãe desaparecida, inclusive Deus como "surda saudade"), e Mia Couto (1955), escritor que trabalha em, ou desde a, dimensão metafísica da saudade. A conclusão para o autor é evidente: "tal como acontece em Angola, a saudade apresenta, aqui, exclusivamente, uma dimensão antropológica, estando dela ausente qualquer voz lírica em que ecoem ou se exprimam as suas dimensões cósmica e divina, diversamente do que ocorre na poesia e na reflexão portuguesa e galega em torno do sentimento saudoso" (p. 61). Não obstante, em poetas como Glória de Sant’Anna ou Rui Knopfli há, talvez, "uma mais viva virtualidade especulativa, uma maior proximidade entre o saber cordial que a saudade proporciona e veicula, e as formas da razão discursiva" (p. 61), sem 
descartar que Mia Couto possa proporcionar, no futuro, novas vias de compreensão do sentido humano, cósmico e transcendente do sentimento saudoso.

O quarto texto, "Expressão e sentido da saudade na poesia cabo-verdiana e santomense" (pp. 62-106), é um amplo e detalhado estudo compreensivo da presença da saudade (como objeto poético, consciência poética e, também, e só, palavra) nos poetas de Cabo Verde, e Santo Tomé e Príncipe. Começa com uma revisão das obras de António Januário Leite (1867-1930), marcada por um pessimismo ultrarromântico e um lirismo doloroso, e Eugénio Tavares (1867-1930), alumbrada desde um lirismo mais otimista e luminoso. Completam a nómina de autores estudados Pedro Cardoso (1890-1942) e José Lopes (1872-1962), poetas da forma “hesperitana” (p. 65) da saudade; Caetano da Costa Alegre (1864-1890) que trabalha a saudade da infância, a juventude, os pais falecidos, a amada morta ou ausente; Marcelo de Veiga (1892-1976); o grupo da revista de arte e letras Claridade formado por Jorge Barbosa (1902-1971), Baltazar Lopes (1907-1989), Manuel Lopes (1907-2005), António Aurélio Gonçalves (1901-1984); Pedro Corsino Azevedo (1905-1942); Sérgio Frusoni (1901-1975), poeta da saudade da infância e o drama da emigração, que dá forma poética à saudade provocada pela ausência forçada; Nuno Miranda (1924); António Nunes (1917-1951); Terêncio Anahory (1932-2000); Gabriel Mariano (1928-2002); Onésimo da Silveira (1935-2021); Ovídio Martins (1928-1999); Yolanda Morazzo (1928-2009); Teobaldo Virgínio (1924-2015); Daniel Filipe (1925-1964); Francisco José Tenreiro (1921-1963); Maria Manuela Margarido (1925-2007); Alda do Espírito Santo (1926-2010); Tomás Medeiros (1931); Rolando Lado-Cruz (1940); Mário Fonseca (1939-2009), entre outros. Os poetas que, entre o final do século XX e o começo do XXI, expressam uma preocupação pela saudade, são José Carlos Fonseca (saudade abordada desde a ironia), José Luiz Tavares (o autor atribui-lhe uma "teoria negativa da saudade") e José Luís Hoppfer Almada (1960) (saudade da infância aldeana, dos colegas, da casa familiar, entre outras). Dentro das expressões poéticas recentes mais significativas de poesia saudosa, no arquipélago santomense encontram-se o poema épico-narrativo Anguéné (1989) de Fernando de Macedo (1928-2006) e a obra lírica de Conceição Lima (1961), cujas qualidades estéticas excedem, com muito, as de Alda Espírito Santo, em opinião do autor. Este estudo minucioso conclui com um ditame razoado: a expressão da saudade nos poetas de Cabo Verde é singular, isenta de dramatismo, associada a uma discreta ironia, com objetos e formas complexos e diversificados que apontam a ecos escatológicos no passado-futuro (o sebastianismo); o mesmo ocorre com a poesia santomense, que aponta a uma dimensão mítico-lendária, isto é, a uma visão da finitude humana que procura uma religação com o tempo passado-futuro. Em palavras do autor "(...) a constância e a variedade da expressão saudosa na poesia africana de língua portuguesa (...) gera em nós a fundada expectativa de que, encerrado o ciclo em que as urgências ideológicas da acção política determinaram e condicionaram toda a cultura, nestes quatro países lusófonos venham a surgir os pensadores capazes de inventar as noções e criar os conceitos adequados a traduzir, discursiva e racionalmente, as intuições, as imagens e as metáforas por que o sentimento saudoso aí se vem revelando e exprimindo, poeticamente" (p. 106).

A segunda parte do livro, que tem como título "Outros estudos sobre a saudade", recolhe cinco trabalhos de datas diversas, de 2011 a 2018.

0 primeiro estudo "Os cem anos do saudosismo de Teixeira de Pascoaes" (pp. 109-123), datado em novembro de 2012, é um repasse e uma revisão dos elementos conceptuais fundamentais que configuram a filosofia saudosista. Começa com uma exposição sumaria do contexto histórico e cultural da segunda década do século XX, em que Teixeira de Pascoaes alumbra a "ontologia e a metafísica da saudade" (p. 111) e que o autor sintetiza, de forma brilhante, em catorze 
teses filosóficas (pp. 111-112). A partir da compreensão da saudade como essência do espírito luso, ou traço distintivo do carácter nacional português, o autor procede a clarificar a filosofia de Pascoaes nos domínios educativos, político e religioso, sem esquecer as reformas políticas e religiosas propostas por Pascoaes desde a filosofia saudosista. Continua o estudo com uma exposição das linhas e orientações fundamentais da reflexão luso-galaica sobre a saudade a partir do feito do saudosismo de Pascoaes. A primeira é de carácter fenomenológico e pretende identificar os elementos constitutivos da consciência saudosa, ao mesmo tempo que compreender a exclusividade do sentimento saudoso. A segunda é de natureza metafísica e abarca três orientações diferentes: antropológica, cosmológica (de tendência panteísta), teológica. Seguidamente o autor procede a apresentar e reflexionar sobre os diversos ângulos da saudade: definições da saudade (procedentes de Joaquim de Carvalho, Sílvio Lima, Eduardo Abranches de Soveral, Eduardo Lourenço, João Ferreiro, Ramón Piñeiro, Daniel Cortezón, Rof Carballo, Miguel Reale); sujeitos da saudade ou entes suscetíveis de sentir saudade (seres humanos conscientes, infantes, animais, Deus no limite); objeto da saudade (pessoas amadas, ausentes ou desaparecidas; terra distante; passado individual vivido ou não); relação com a reminiscência platónica e o mito; a temporalidade específica da saudade. Conclui o estudo lembrando brevemente alguns autores associados às três orientações da problemática ontológica e metafísica: antropológica (Fernando Pessoa, Ramón Piñeiro, García Sabell), cosmológica (Teixeira de Pascoaes, Rof Carballo, Daniel Cortezón), teológica (Leonardo Coimbra, António Dias de Magalhães, José Marinho, Alfonso Botelho, Dalila Pereira da Costa, Pinharanda Gomes, Manuel Ferreira Patrício, Andrés Torres Queiruga, Paulo Borges, Manuel Cândido Pimentel, Samuel Dimas). Por último, o autor acrescenta uma breve, mas intensa reflexão, sobre a saudade como realidade imanente e/ou transcendente que, pela sua riqueza intrínseca, proporciona sem cessar novos caminhos de investigação para a filosofia luso-galaica.

O segundo estudo "A reflexão sobre a saudade na geração «Nós»" (pp. 124-134), datado em junho de 2018, é uma análise detalhada e clarificadora da contribuição da geração de escritores e intelectuais galegos de 1916 (geração "Nós") à reflexão sobre o sentimento saudoso, e o seu contributo à constituição da filosofia galega da saudade que, de algum modo, possibilitou a sua afirmação mais sistémica a partir da geração galega de 1950 (geração “Galaxia”). 0 autor estuda a saudade em Ramón Cabanillas, Vicente Risco, Xaime Quintanilla e Ramón Otero Pedrayo. A reflexão destes escritores e intelectuais desenvolve-se em "estreito diálogo" (p. 134) com o saudosismo de Teixeira de Pascoaes (1877-1952) e, em menor medida, com o criacionismo de Leonardo Coimbra (1883-1936). 0 autor conclui o seu percurso pelas obras destes escritores de "Nós" com uma valorização da filosofia galega da saudade elaborada anteriormente a eles: "(...) no ciclo seguinte, iniciado três decénios depois, quebrado ou suspenso o laço ou a relação cultural com Portugal e ignorando, incompreensivelmente, tanto os caminhos da filosofia portuguesa da saudade (Joaquim de Carvalho, Afonso Botelho, António Dias de Magalhães, Sílvio Lima) como os da filosofia espanhola contemporânea (Unamuno, Zubiri, Zambrano, Laín, Marías), passa a referir-se, quase exclusivamente, à filosofia alemã, e, de modo particular, ao pensamento de Heidegger" (p. 134).

0 terceiro estudo "A estética da saudade de Afonso Botelho" (pp. 135-144), com data de junho de 2016, é uma concisa explicação da reflexão estética de Afonso Botelho (1919-1996) que toma como base, ou ponto de partida, a arte portuguesa para, desde a sua particular concreção, ascender ao plano universal dos conceitos, símbolos e princípios que sustentam, ou fundamentam, a disciplina filosófica das formas em que o Belo adquire expressão sensível e inteligível. Na estética filosófica de Botelho a obra de arte entende-se como um objeto no qual a visão, a forma e o conteúdo se encontram relacionados de um modo indissolúvel, razão pela qual a sua análise 
exige abordar a "«equação lógica»" (p. 136) desses elementos. Assim, neste estudo, o autor expõe e explica os conceitos estéticos indispensáveis para compreender a filosofia de Botelho: sensação englobante, emoção estética, situação estética, visão plástica, momento plástico, símbolo, imagem, palavra (tipos e momentos), princípio de movimento (que faz da "estética" um movimento transcendente superador de qualquer "estática"), princípio de convergência (que revela a memória como dimensão originaria frente à sua fragmentação sempre parcial e derivada).

O quarto estudo "Ortega e a saudade" (pp. 145-153) datado em outubro de 2017, é um trabalho de contextualização, exposição e valorização das notas que o filósofo espanhol Ortega e Gasset esboçou em Lisboa, em outubro de 1943, sobre o assunto da saudade. Ainda que, certamente, Ortega só pretendia traçar uma "fisionomia" do carácter, ou natureza portuguesa da saudade, não consegue situá-la além do plano do mito, ou da mitologia, concebidos em sentido vulgar. Além disso, a respeito da dimensão histórica da saudade “(...) para Ortega, a saudade seria como uma solidificação de todo o horizonte, como um quedar-se no habitual, o costumeiro, uma radical recusa de aventura" (p. 148). Para o autor, as notas breves e fragmentárias de Ortega suscitam sérias dúvidas e interrogantes severos. Primeiro, ao atribuir à saudade a categoria de mito, ignora a sua condição de sentimento complexo que não se esgota na sua dimensão amorosa ou erótica, nem se origina unicamente na ausência ou distância. Segundo, desconhece a temporalidade específica da saudade, que porta em si um elemento de invenção e criação que não é meramente reprodutivo. Terceiro, a saudade não é resultado da imaginação coletiva de um povo referida a um arquétipo mítico ou intemporal, senão uma disposição sentimental de uma alta complexidade e sofisticação cultural. Quarto, a saudade tem uma relação inextricável e permanente com as descobertas geográficas de Portugal, que lhe confere uma dimensão cósmica e metafísica, jamais encerrada em si mesma e negadora do outro diverso (imanente ou transcendente). Por último, a saudade também engloba o conhecimento, a poesia e a história do povo galego, dado que Ortega desconhece ou esquece. 0 autor conclui o seu estudo com o esboço do que considera uma mais autêntica relação entre saudade e mito: a que estabelecem Vergílio Ferreira e, sobretudo, Eduardo Lourenço.

O quinto e último estudo "Da possibilidade de pensar a saudade a partir da filosofia espanhola contemporânea" (pp. 154-170), de outubro de 2011, surge da constatação de um facto acontecido na cultura galega e a ideação de uma proposta de renovação que desenvolve, e prolonga, o diagnóstico elaborado no segundo estudo "A reflexão sobre a saudade na geração "Nós»". 0 facto é que desde que Ramón Cabanillas (1876-1959) pensou a dimensão saudosa da poesia galega (com base na teoria de Teixeira de Pascoaes), as reflexões teóricas mais relevantes sobre a saudade levadas a cabo em Galiza se desenvolvem, quase exclusivamente, em diálogo com o pensamento alemão e a filosofia de Heidegger. Ante esta situação, o autor propõe uma nova via: explorar a possibilidade de entender e pensar o sentimento saudoso a partir da filosofia espanhola contemporânea que é "(...) decerto mais próxima ou afim do pensar galego do que a filosofia germânica" (p. 154). 0 autor analisa e aprofunda nas potencialidades dos conceitos de irracional (Unamuno), religação (Zubiri), esperança (Laín Entralgo), razão poética (María Zambrano), ilusão (Julián Marías), inspirado e guiado pelos trabalhos sobre a saudade do filósofo e teólogo galego Andrés Torres Queiruga. 0 autor conclui que, apesar do que fez a generalidade dos pensadores galegos do nosso tempo, é possível encontrar no pensamento dos filósofos analisados, ou de outros filósofos espanhóis do século XX, perspetivas, conceitos e noções que possibilitam abordar, especulativamente, o sentido e valor metafísico do sentimento saudoso, e fundar uma nova, ou diversa, compreensão filosófica da saudade. 